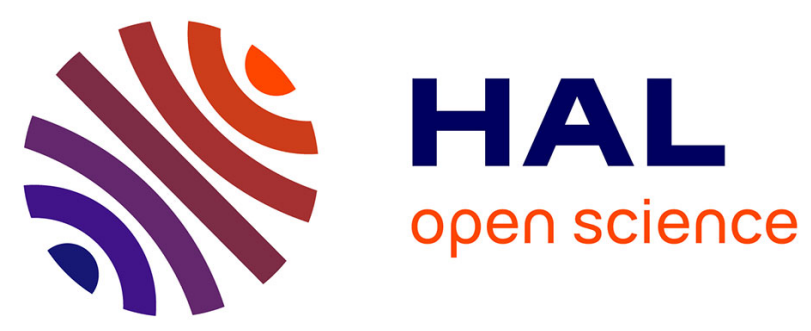

\title{
Design and Synthesis of a Caged Carboxylic Acid with a Donor- $\pi$-Donor Coumarin Structure: One-photon and Two- photon Uncaging Reactions Using Visible and Near-Infrared Lights
}

\author{
Youhei Chitose, Manabu Abe, Ko Furukawa, Jhe-Yi Lin, Tzu-Chau Lin, \\ Claudine Katan
}

\section{To cite this version:}

Youhei Chitose, Manabu Abe, Ko Furukawa, Jhe-Yi Lin, Tzu-Chau Lin, et al.. Design and Synthesis of a Caged Carboxylic Acid with a Donor- $\pi$-Donor Coumarin Structure: One-photon and Two- photon Uncaging Reactions Using Visible and Near-Infrared Lights. Organic Letters, 2017, 19 (10), pp.26222625. 10.1021/acs.orglett.7b00957 . hal-01527343

HAL Id: hal-01527343

https://hal-univ-rennes1.archives-ouvertes.fr/hal-01527343

Submitted on 30 May 2017

HAL is a multi-disciplinary open access archive for the deposit and dissemination of scientific research documents, whether they are published or not. The documents may come from teaching and research institutions in France or abroad, or from public or private research centers.
L'archive ouverte pluridisciplinaire HAL, est destinée au dépôt et à la diffusion de documents scientifiques de niveau recherche, publiés ou non, émanant des établissements d'enseignement et de recherche français ou étrangers, des laboratoires publics ou privés. 
DOI: 10.1021/acs.orglett.7b00957 Org. Lett. 2017, 19, 2622-2625

\title{
Design and Synthesis of a Caged Carboxylic Acid with a Do- nor-m-Donor Coumarin Structure: One-photon and Two- photon Uncaging Reactions Using Visible and Near-Infrared Lights
}

\author{
Youhei Chitose ${ }^{1}$, Manabu Abe** ${ }^{1}$, Ko Furukawa ${ }^{2}$, Jhe-Yi Lin ${ }^{3}$ Tzu-Chau Lin, ${ }^{*}$ Claudine Katan*4 \\ ${ }^{1}$ Department of Chemistry, Graduate School of Science, Hiroshima University, 1-3-1 Kagamiyama, Higashi-Hiroshima, \\ Hiroshima 739-8526, Japan. ${ }^{2}$ Centre for Instrumental Analysis, Niigata University, 8050 Ikarashi 2-no-cho, Nishi-ku, Niiga- \\ ta 950-2181, Japan. ${ }^{3}$ Photonic Materials Research Laboratory, Department of Chemistry, National Central University, \\ Jhong-Li District, Taoyuan City 32001, Taiwan. ${ }^{4}$ Institut des Sciences Chimiques de Rennes, UMR 6226, CNRS, Université \\ Rennes 1, 35042 Rennes, France
}

\begin{abstract}
A caged carboxylic acid with a novel TP-responsive $\mathrm{D}$ (donor)- $\pi$-D coumarin backbone with a quadrupolar nature was designed and synthesized in this study. The newly synthesized coumarin derivative showed a strong one-photon (OP) absorption band $(\varepsilon \sim 29000$ $\left.\mathrm{cm}^{-1} \mathrm{M}^{1}\right)$ in the visible region $(>\sim 400 \mathrm{~nm})$. Time-dependent density functional theory calculations predicted a sizable TP absorption crosssection with a maximum at $\sim 650 \mathrm{~nm}$ significantly lager than that related to the OP absorption band. This is confirmed experimentally using TP excited fluorescence in the fs regime that leads to TPA cross-section of $18 \mathrm{GM}$ and $5.6 \mathrm{GM}$ at $680 \mathrm{~nm}$ and $760 \mathrm{~nm}$, respectively. The OP pho-

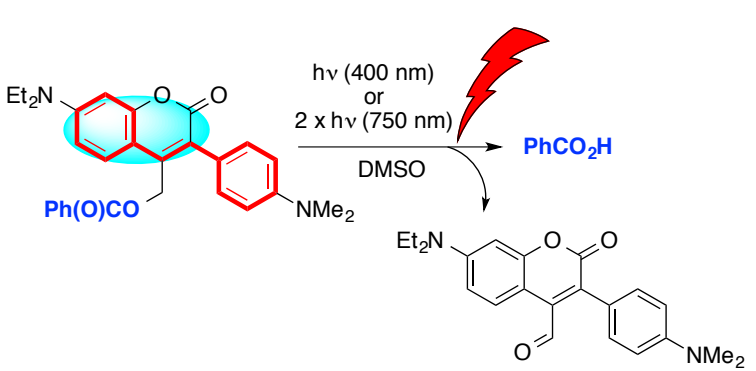
tolysis $(400 \mathrm{~nm})$ and NIR-TP photolysis $(750 \mathrm{~nm})$ of the caged benzoic acid resulted in a clean formation of benzoic acid and an aldehyde.
\end{abstract}

Caged compounds, which are temporally inactivated forms of bioactive substances by photolabile-protecting groups (PPGs), are widely used in various studies to understand the behaviors of bioactive compounds. ${ }^{1-4}$ The phototriggered release of bioactive molecules (drugs) without using any chemical reagents plays an important role in physiological studies.

Coumarin-based caged compounds (CM-drug) were developed by Givens and Matuszewski (Figure 1). ${ }^{5}$ The fast release of bioactive compounds (drug) from the singlet excited state, ${ }^{1}[\mathrm{CM} \text {-drug }]^{*}$, is an advantage that allows their use in physiological studies. ${ }^{6,7}$ However, coumarins exhibit absorption wavelength in the region $280-300 \mathrm{~nm}^{8,9} \mathrm{UV}$ irradiation is needed to generate the excited state using one-photon (OP) excitation, causing cell damage. The unfavorable damage can be avoided by red-shifting the absorption maximum to the visible-light region. This has been achieved by the introduction of electron-donating and/or withdrawing substituents at the $\mathrm{C} 5-\mathrm{C} 8$ positions. ${ }^{10-12}$

Two-photon (TP) excitation processes using light in the near-infrared (NIR) region, 650-1050 nm, are advantageous for physiological studies, because deep penetration and a high spatial resolution can be achieved. ${ }^{13-16}$ The development of new NIR-TP-responsive chromophores is currently a state-ofthe-art challenge. Several $\pi$-extended coumarin derivatives with TP absorption (TPA) character have been synthesized. ${ }^{17-}$ 22 Furuta et al. developed a TP-responsive (6-bromo-7-

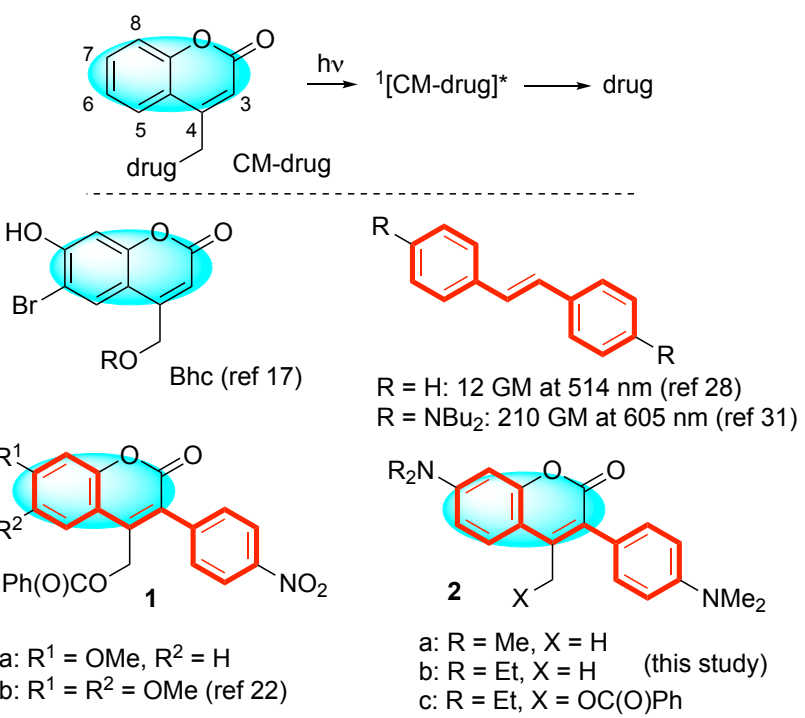

Figure 1. Photochemical uncaging reaction. Coumarin-based Chromophores with TPA character.

hydroxycoumarin-4yl)methyl (Bhc) group (Figure 1), ${ }^{17}$ which has a TP uncaging efficiency $\left(\delta_{\mathrm{u}}\right)$ of $\sim 1 \mathrm{GM}$ at $740 \mathrm{~nm}\left(\delta_{\mathrm{u}}=\sigma_{2}\right.$ 
$\times \phi_{u}$, where $\sigma_{2}$ is the TPA cross-section $(\mathrm{GM})^{23}$ and $\phi_{u}$ is the uncaging quantum yield). A higher TP efficiency would be better for physiological studies. ${ }^{24}$

So far, we have designed and synthesized TP chromophores with a stilbene core as the platform, ${ }^{25-27}$ because stilbene itself has a relatively large TPA cross-section, $12 \mathrm{GM}$ at $514 \mathrm{~nm}$, despite a small $\pi$ conjugation system. ${ }^{28}$ Donor (D)-acceptor (A) $\pi$-conjugated ${ }^{29}$ coumarin derivatives 1 (Figure 1) showed TP-induced uncaging in the NIR region, in which an electronwithdrawing group was introduced at the C3 position. ${ }^{22}$ However, low quantum yields of 0.09 and 0.03 were observed for the uncaging reactions of $\mathbf{1 a}$ and $\mathbf{1 b}$, respectively, decreasing the efficiency of the TP-induced uncaging reactions.

This paper describes the synthesis and reactivity of a novel $D-\pi$-D conjugated coumarin-based caged compound 2 (Figure 1 ), in which the D-substitution at the $C 3$ position was achieved for the first time. The D- $\pi$-D structural motifs were reported to significantly enhance the TPA character in stilbene cores because of a large change in quadrupole moment during the electronic excitation process. ${ }^{30,31}$ For example, 4,4'-bis(di- $n$ butylamino)- $E$-stilbene was reported to exhibit a large TP cross-section of $210 \mathrm{GM}$ at $605 \mathrm{~nm}$ (Figure 1). Such a high TP cross-section due to the D- $\pi$-D structural motif is worthy of application in caged compounds. The D- $\pi$-D structural motif by introducing the donating substituent at the $\mathrm{C} 3$ position has not been applied so far to coumarin-4ylmethyl type of caged compounds.

First, the OP absorption (OPA) and TPA spectra of a coumarin derivative 2a were predicted using density functional theory (DFT) and time-dependent (TD) DFT approaches (Figure 2 ). The computational details are provided in Supporting Information. The predicted first absorption maximum of 7dimethylamino-substituted coumarin $\left(\mathrm{S}_{0} \rightarrow \mathrm{S}_{1}\right.$ transition) is slightly blue-shifted compared to its D- $\pi$-A analogue 1a (Figure S19 $)^{22}$. As expected for a D- $\pi$-D chromophores, a large TPA cross-section (of ca. $700 \mathrm{GM}$ at this level of theory, see discussion on the supporting information for more details) was found for 2a near $650 \mathrm{~nm}$, corresponding to the $\mathrm{S}_{0} \rightarrow \mathrm{S}_{2}$ electronic transition. Such a larger TPA cross-section of the second electronic transition $\left(\mathrm{S}_{0} \rightarrow \mathrm{S}_{2}\right)$ as compared to that of the first electronic transition $\left(\mathrm{S}_{0} \rightarrow \mathrm{S}_{1}\right)$ is similar to the one reported on $4,4^{\prime}$-bis(di- $n$-butylamino)- $E$-stilbene ${ }^{31}$. These computational predictions inspired us to synthesize caged benzoic acid 2c, in which the OPA should occur in the visible region whereas TP uncaging should be possible using excitation in the NIR region.

7-(Diethylamino)-3-(4-(dimethylamino)phenyl)-4-methyl$2 H$-chromen-2-one (2b) with a D- $\pi$-D $\pi$-conjugated coumarin chromophore was synthesized as shown in Scheme 1. Bromination of commercially available 7-diethylamino-substituted coumarin 3 gave compound $4 ;^{21}$ subsequent coupling with the pinacol ester of 4-dimethylaminophenyl boronic acid afforded 2b. Consistently with the TD-DFT prediction, compound $\mathbf{2 b}$ showed a first OPA band with an absorption maximum at 386 $\mathrm{nm}\left(\varepsilon=28861 \mathrm{~cm}^{-1} \mathrm{M}^{1}\right)$ in DMSO (Figure S11).

The TPA spectrum of compound $2 \mathbf{b}\left(1.0 \times 10^{4} \mathrm{M}\right)$ was

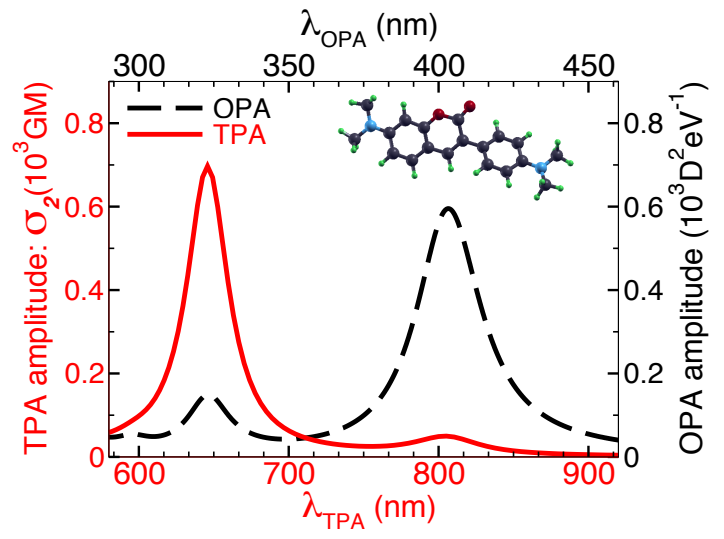

Figure 2. Computed OPA (right-hand axis) and TPA (left-hand axis) spectra at the TD-B3LYP/6-31G(d)//B3LYP/6-31G(d) level of theory for a coumarin derivative $\mathbf{2 a}$, in vacuum and using a damping factor of $0.10 \mathrm{eV}$ to simulate the finite linewidth in the resonant spectra.

Scheme 1. Synthesis of compound $2 \mathbf{b}$ and $2 \mathbf{c}$.

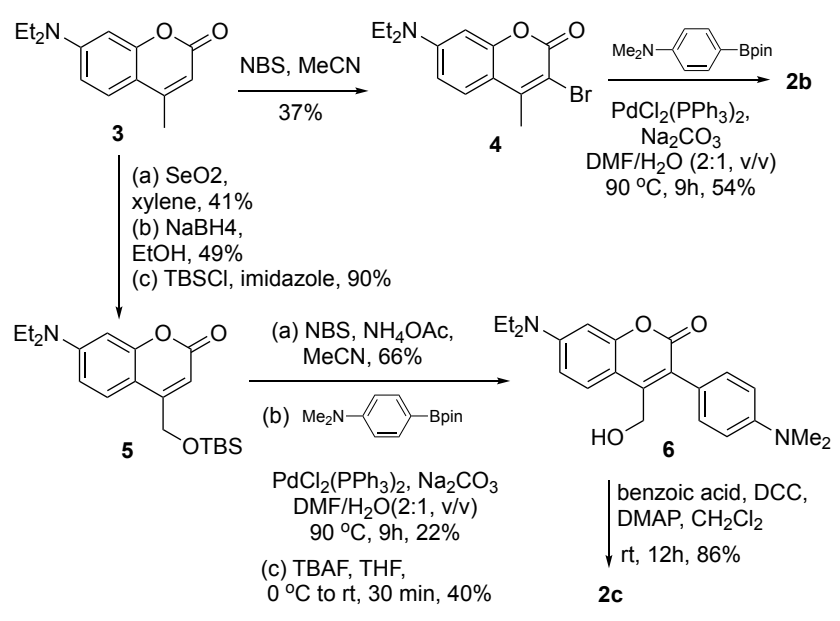

measured using the TP excitation fluorescence method in toluene, even though the dynamic tuning range of our laser system for the measurements is limited over $680-\mathrm{nm}$ excitation wavelength (Figure 3 ). As predicted by the TD-DFT calculations (Figure 2), the TPA cross-section of the second electronic transition $\left(\mathrm{S}_{0} \rightarrow \mathrm{S}_{2},<680 \mathrm{~nm}\right)$ was much larger than that of the first electronic transition $\left(\mathrm{S}_{0} \rightarrow \mathrm{S}_{1}, \sim 760 \mathrm{~nm}\right)$, i.e., $5.6 \mathrm{GM}$ at $760 \mathrm{~nm}$ and $18 \mathrm{GM}$ at $680 \mathrm{~nm}$.

Compound 2c was also synthesized from compound $\mathbf{3}$ (Scheme 1). After the oxidation of 3 with $\mathrm{SeO}_{2}$ and pro- tection of the alcohol, the rigid $D-\pi-\mathrm{D}$ stilbene structure was prepared by introducing the electron-donating group at the $\mathrm{C} 3$ position using the coupling of the bromide with the commercially available pinacol ester of 4-dimethylaminophenyl boronic acid. The corresponding 4- hydroxy methyl derivative 6 was synthesized by deprotection. Caged benzoic acid 2c was obtained by condensation with benzoic acid in a high yield (86\%). The UV-visible absorption spectrum of compound 2c showed the maximum absorption at $407 \mathrm{~nm}\left(\varepsilon_{407 \mathrm{~nm}}=28493\right.$ $\mathrm{M}^{1} \mathrm{~cm}^{-1}$ ) in DMSO (Figure S14). 


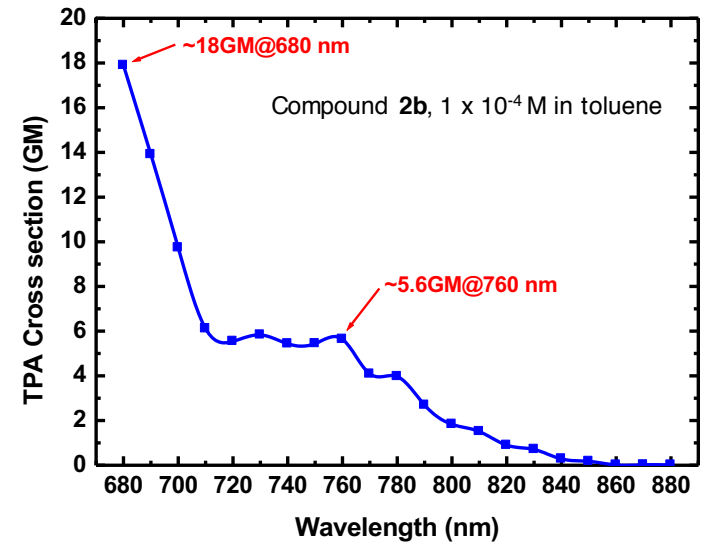

Figure 3. TPA spectrum, $680-880 \mathrm{~nm}$, of compound $\mathbf{2 b}(1.0 \times$ $\left.10^{4} \mathrm{M}\right)$ in toluene.

The OP photolysis of compound $\mathbf{2 c}$ was conducted using a Xe lamp at $400 \pm 10 \mathrm{~nm}$ in DMSO-d $\mathrm{d}_{6}(1.8 \mathrm{mM})$, resulting in the quantitative uncaging of benzoic acid (Eq. 1, Figure 4). The quantum yield $\left(\phi_{u}\right)$ was determined to be 0.16 . After 2-h irradiation, the photoproduct 4- carboxaldehyde coumarin 7 was isolated in $70 \%$ yield along with benzoic acid $(\sim 95 \%)$. The formation of an aldehyde was observed for the first time in related uncaging reactions using coumarin derivatives. The clean photochemical transformation of $\mathbf{2 c}$ was also confirmed by analysis of UV-visible absorption spectra (Figure 5). Thus, aldehyde 7 with $\lambda_{\max }=482 \mathrm{~nm}\left(\varepsilon 23178 \mathrm{~cm}^{-1} \mathrm{M}^{-1}\right)$ was observed with a concomitant decay of the band of $2 \mathrm{c}$ with $\lambda_{\max }$ $407 \mathrm{~nm}$.
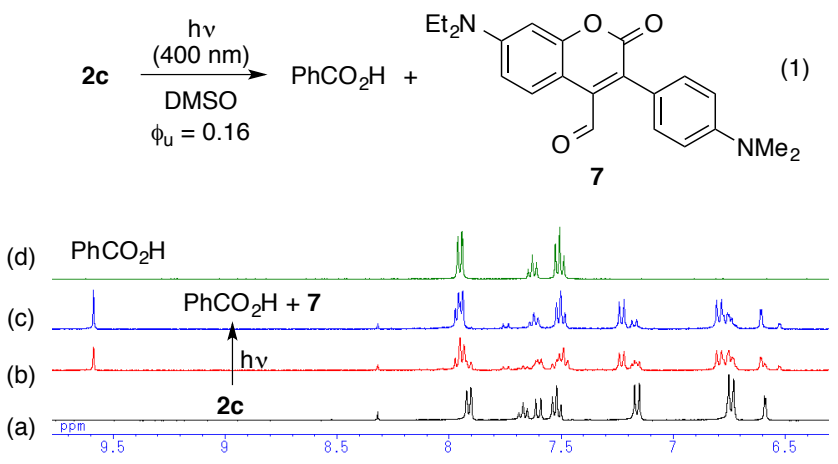

Figure 4. OP uncaging reaction of compound $2 \mathrm{c}$ at $400 \pm 10 \mathrm{~nm}$ in DMSO- $\mathrm{d}_{6}$; (a) ${ }^{1} \mathrm{HNMR}$ spectrum of compound $2 \mathbf{c}$ in DMSO- $d_{6}$ before the irradiation; (b) after 1-h photolysis using $400 \mathrm{~nm}$ (b); after 2-h photolysis; (c) ${ }^{1} \mathrm{HNMR}$ spectrum of benzoic acid in DMSO- $d_{6}$.

The effect of solvent on the OP photolysis of compound 2c was investigated using methanol, DMSO with 5\% Tris buffer, and DMSO with 5\% distilled water (Figure 6). The uncaging reaction rates of coumarin-4ylmethyl type caged compounds were reported to be fast in the presence of water in solvents. ${ }^{18}$ Interestingly, the uncaging reaction of $\mathbf{2 c}$ in methanol was slower than the reaction in anhydrous or wet DMSO $(5 \%$ tris buffer) by a factor of 1.6 (Figure 6). However, the reaction rate of uncaging of $\mathbf{2 c}$ in wet DMSO (5\% water) was slightly faster than anhydrous DMSO by a factor of 1.2 (Figure 6). 4Hydroxymethyl derivative 6 was isolated in $76 \%$ isolated yield in wet DMSO in place of aldehyde 7 in anhydrous DMSO (Scheme 2). The formation of photoproducts clearly suggests that carbocation $\mathbf{8}$ is generated in the photochemical reaction, which is trapped by DMSO or $\mathrm{H}_{2} \mathrm{O}$, affording aldehyde 7 or alcohol $\mathbf{6}$ (Scheme 2). ${ }^{6}$ The significantly short lifetime of ${ }^{1} \mathbf{2} \mathbf{c}^{*}$ fluorescence (577 ps in DMSO) in comparison with ${ }^{1} \mathbf{2 b}^{*}$ (3.1 ns, Figures S12,S13) supports the fast release of benzoic acid from ${ }^{1} \mathbf{c}^{*}$ (Figures S15, S16).

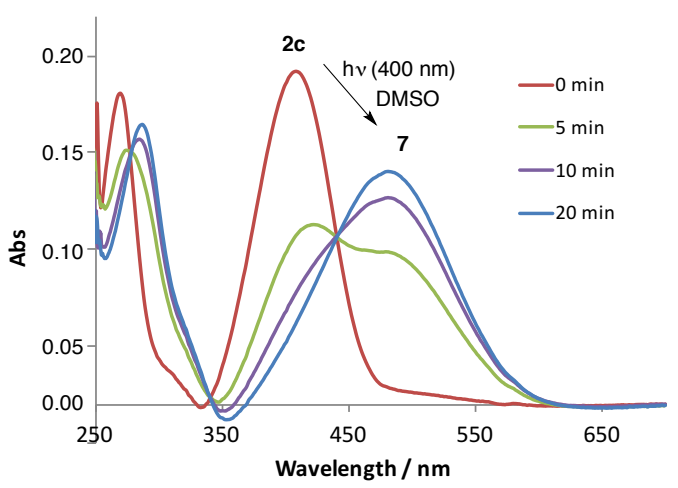

Figure 5. UV-visible spectroscopic analysis of OP uncaging reaction of caged benzoate $2 \mathrm{c}$ at $400 \pm 10 \mathrm{~nm}$ irradiation in DMSO.

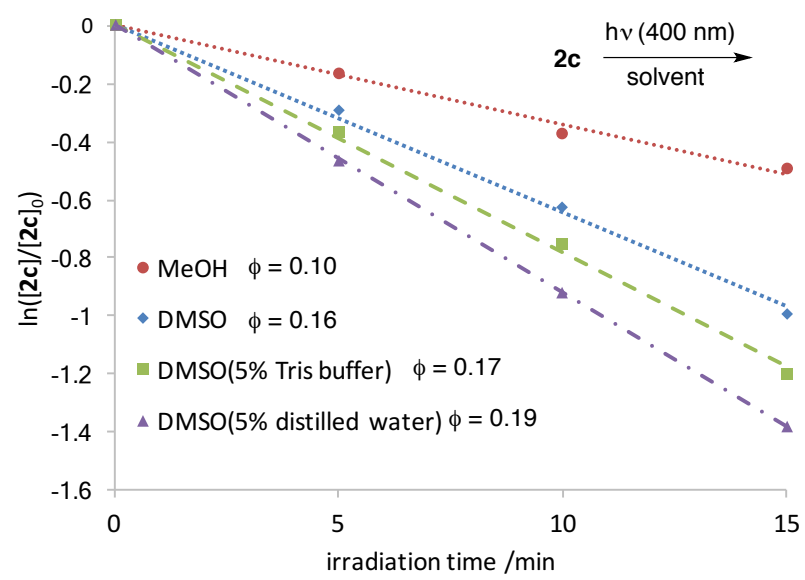

Figure 6. Time profile of the OP uncaging of compound 2c, $\ln [\mathbf{2 c}] /[2 \mathbf{c}]_{\text {o }}$ vs. irradiation time $(\mathrm{min})$ at a wavelength of $400 \mathrm{~nm}$ using a Xe lamp in various solvents.

Finally, the TP photolysis of compound $2 \mathrm{c}\left(5 \times 10^{-2} \mathrm{mM}\right)$ was carried out in DMSO using 750-nm light obtained from a Ti:sapphire laser (pulse width $100 \mathrm{fs}, 80 \mathrm{MHz}$ ) at an average power of $700 \mathrm{~mW}$ (Figure S17). The TP-uncaging reaction of 2c was observed at $750 \mathrm{~nm}$, and the uncaging rate was determined to be $k_{750}=1.9 \times 10^{-6} \mathrm{~s}^{-1}$. The TPA cross-section of $2 \mathrm{c}$ was extrapolated to $\sim 7 \mathrm{GM}$ at $750 \mathrm{~nm}$ by comparing the uncaging rate constant of $9.4 \times 10^{-6} \mathrm{~s}^{-1}$ of the standard compound NPBF-BA $\left(\sigma_{2}=54 \mathrm{GM} \text { and } \phi_{\mathrm{u}}=0.09\right)^{26}$. This TPA crosssection is consistent with the TPA spectrum recorded for $\mathbf{2 b}$ (Figure 3). Although we cannot experimentally measure the TPA cross-section value of $\mathbf{2 b}$ below $680 \mathrm{~nm}$, due to the limitation of our laser setup, the cross-section at the maximum can be extrapolated from the computationally predicted crosssections by using simple proportionality method as described in the SI. Therefore, the maximal TPA cross-section of compound $2 \mathrm{c}$ can be estimated to reach $\sim 100 \mathrm{GM}$ around $650 \mathrm{~nm}$. The corresponding TP uncaging efficiency was then estimated to be $\sim 16 \mathrm{GM}$ (= $100 \times 0.16)$, which is one order of magnitude larger than that of related dipolar coumarin derivatives. 
In this study, a novel caged carboxylic acid with a TPresponsive $\mathrm{D}-\pi-\mathrm{D}$ coumarin backbone was designed and synthesized. The newly synthesized $D-\pi-D$-substituted coumarin derivative showed a strong OPA band $\left(\varepsilon \sim 29000 \mathrm{~cm}^{-1} \mathrm{M}^{1}\right)$ in the visible region $(>\sim 400 \mathrm{~nm})$. TD-DFT calculations predicted that the TP excitation process of the second electronic transition is allowed, with a maximum of several hundreds of $\mathrm{GM}$ at $\sim 650 \mathrm{~nm}$. Meanwhile, the TPA cross-section of the first electronic transition close to $800 \mathrm{~nm}$ was predicted to be much smaller, as a result of the quadrupolar nature of the investigated compound. In fact, the experimental TPA cross-section at $680 \mathrm{~nm}$ was found three times larger $(18 \mathrm{GM})$ than that recorded in the vicinity of twice the wavelength of the main OPA band (5.6 GM at $760 \mathrm{~nm}$ ). The OP photolysis of $2 \mathrm{c}$ with a D$\pi$-D coumarin backbone in DMSO resulted in a clean formation of benzoic acid and an aldehyde 7, hitherto unknown in coumarin-4yl methyl type uncaging reactions. The quantum yield of 0.16 was much higher than the D- $\pi$-A-substituted coumarin derivative. In the presence of $\mathrm{H}_{2} \mathrm{O}$, alcohol 6 was formed in place of the aldehyde, suggesting the generation of coumarin 4-ylmethyl cation $\mathbf{8}$ in the uncaging reaction. This new platform for the TP-induced uncaging reaction can be applied to future in vivo physiological studies.

Scheme 2. Mechanism for the uncaging reaction of $2 \mathbf{c}$ in anhydrous DMSO and wet DMSO.

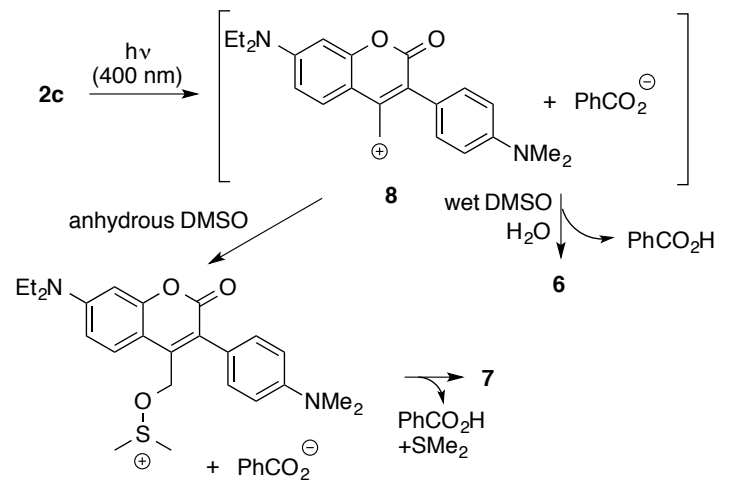

\section{Supporting Information}

The Supporting Information is available free of charge on the ACS Publications website.

Computational and experimental details, ${ }^{1} \mathrm{H}$ and ${ }^{13} \mathrm{C}$ NMR spectra for new compounds (PDF)

\section{AUTHOR INFORMATION}

\section{Corresponding Author}

mabe@hiroshima-u.ac.jp

tclin@ncu.edu.tw

claudine.katan@univ-rennes1.fr

\section{ACKNOWLEDGMENT}

NMR and MS measurements were performed at N-BARD, Hiroshima University. M.A. gratefully acknowledges the financial support by a Grant- in-Aid for Science Research on Innovative Areas "Stimuli-responsive Chemical Species (No. 2408)" (JSPS KAKENHI Grant No. JP24109008) and JP17H0302200. TCL acknowledges the financial support from the Ministry of Science and Technology (MOST), Taiwan (Grant No. MOST 105-2113M-008-004). C.K. acknowledges the HPC resources of CINES and IDRIS under the allocations 2016-[x2016080649] made by GENCI.

\section{REFERENCES}

(1) In Dynamic Studies in Biology, Eds. Goeldner, M.; Givens, R., Wiley-VCH, 2005.

(2) Engels, J.; Schlager, E.-J. J. Med. Chem. 1977, 20, 907-911.

(3) Kaplan, H.; Forbush, B.; Hpffmann, J. F. Biochemistry, 1978, 17, 1929-1935.

(4) Klán, P.; Šolomek, T.; Bochet, C. G.; Blanc, A.; Givens, R.; Rubina, M.; Popik, V.; Kostikov, A.; Wirz, J. Chem. Rev. 2013, 113, 119-191.

(5) (a) Givens, R. S.; Matuszewski, B. J. Am. Chem. Soc. 1984, 106, 6860-6861. (b) Kamatham, N.; Mendes, D. C.; Da Silva, J. P.; Givens, R. S.; Ramamurthy, V. Org. Lett. 2016, 18, 5480-5483.

(6) Schmidt, R.; Geissler, D.; Hagen, V.; Bendig, J. J. Phys. Chem. $A$, 2007, 111, 5768-5774.

(7) Atta, S.; Jana, A.; Ananthakirshnan, R.; Dhuleep, P. S. N. J. Agric. Food Chem. 2010, 58, 11844-11851.

(8) Wheelock, C. E. J. Am. Chem. Soc. 1959, 81, 1348-1352.

(9) Jivaramonaikul, W.; Rashatasakhon, P.; Wanichwecharrungruang, S. Photochem. Photobiol. Sci. 2010, 9, 1120-1125.

(10) Givens, R. S.; Rubina, M.; Wirz, J. Photochem. Photobiol. Sci. 2012, 11, 472-488.

(11) Li, J.; Zhang, C.-F.; Yang, S.-H.; Yang, W.-C.; Yang, G.-F. Anal. Chem. 2014, 86, 3037-3042.

(12) Furuta, T. In Dynamic Studies in Biology, Eds. Goeldner, M.; Givens, R., Wiley-VCH, 2005, 29-55.

(13) Matsuzaki, M.; Ellis-Davies, G. C. R.; Nemoto, T.; Miyashita, Y.; Iino, M.; Kasai, H. Nat. Neurosci. 2001, 4, 1086.

(14) Ellis-Davies, G. C. R. Nat Methods. 2007, 4(8), 619-628.

(15) Brieke, C.; Rohrbach, F.; Gottschalk, A.; Mayer G.; Heckel, A. Angew. Chem., Int. Ed., 2012, 51, 8446-8476

(16) Bort, G.; Gallavardin, T.; Ogden, D.; Dalko, P. I. Angew. Chem. Int. Ed. 2013, 52, 4526-4537.

(17) Furuta, T.; Wang, S. S.-H.; Dantzker, J. L.; Dore, T. M.; Bybee, W. J.; Callaway, E. M.; Denk, W.; Tsien, R. Y. Proc. Natl. Acad. Sci. U.S.A. 1999, 96, 1193-1200.

(18) Suzuki, A. Z.; Watanabe, T.; Kawamoto, M.; Nishiyama, K.; Yamashita, H.; Ishii, M.; Iwamura, M.; Furuta, T. Org. Lett., 2003, 5, 4867-4870

(19) Bao, C.; Fan, G.; Lin, Q.; Li, B.; Cheng, S.; Huang, Q.; Zhu, L. Org. Lett., 2012, 14, 572-575.

(20) Sakamoto, Y.; Boinapally, S.; Katan, C.; Abe, M. Tetrahedron Lett., 2013, 54, 7171-7174.

(21) Olson, J. P.; Banghart, M. R.; Sabatini, B. L.; Ellis-Davies, G. C. R. J. Am. Chem. Soc. 2013, 135, 15948-15954.

(22) Chitose, Y.; Abe, M.; Furukawa, K.; Katan, C. Chem. Lett. 2016, 45, 1186-1188.

(23) Göppert-Mayer, M. Ann. Phys. 1931, 401, 273-294.

(24) Kiskin, N. I.; Chillingworth, R.; McCray, J. A.; Piston, D.; Ogden, D. Eur. Biophys. J. 2002, 30, 588-604.

(25) Boinapally, S.; Huang, B.; Abe, M.; Katan, C.; Noguchi, J.; Watanabe, S.; Kasai, H.; Xue, B.; Kobayashi, T. J. Org. Chem. 2014, 79, 7822-7830

(26) Komori, N.; Jakkampudi, S.; Motoishi, R.; Abe, M.; Kamada, K.; Furukawa, K.;Katan, C.; Sawada, W.; Takahashi, N.; Kasai, H.; Xue, B.; Kobayashi, T. Chem. Commun. 2016, 52, 331-334.

(27) Jakkampudi, S.; Abe, M.; Komori, N.; Takagi, R.; Furukawa, K.; Katan, C.; Sawada, W.; Takahashi, N.; Kasai, H. ACS Omega, 2016, $1,193-201$

(28) Anderson, R. J. M.; Holtom, G. R.; McClain, W. M. J. Chem. Phys. 1979, 70, 4310-4315.

(29) Boyd, R. W. In Nonlinear Optics, 2nd ed., 2003, 515.

(30) Wang, X.; Wang, D.; Zhou, G.Y.; Yu, W. T.; Zhou, Y. F.; Fang, Q.; Jiang, M. H. J. Mater. Chem., 2001, 11, 1600-1605.

(31) Albota, M.; Beljonne, D.; Bre'das, J. L.; Ehrlich, J. E.; Fu, J. Y.; Heikal, A. A.; Hess, S. E.; Kogej, T.; Levin, M. D.; Marder, S. R.; Maughon, D. M. C.; Perry, J. W.; Röckel, H.; Rumi, M.; Subramaniam, G.; Webb, W. W.; Wu, X. L.; Xu, C. Science, 1998, 281, 16531656. 